\title{
Crescimento sustentável da economia brasileira: há um dilema entre o equilíbrio interno e externo?
}

João Basílio Pereima Neto

Márcio José Vargas da Cruz ${ }^{* *}$

\begin{abstract}
RESUMO - Este artigo discute a sustentabilidade do atual ciclo de crescimento da economia brasileira. Ao longo dos último 60 anos o país teve apenas dois ciclos longos de crescimento, que duraram 15 anos aproximadamente cada um. O último vigorou entre 1966-1981. Dos anos 1980 até 2004 vigorou um padrão cíclico de crescimento culminando numa sucessão de seis ciclos de expansão e retração. No conjunto estes mini ciclos causaram um rebaixamento da taxa de crescimento de longo prazo. Parte da explicação dos ciclos longos e dos ciclos curtos recentes é explicada pelo comportamento das contas externas. O último ciclo de expansão (atual) teve um empuxo inicial causado pelo aumento de exportação, em decorrência da desvalorização cambial ocorrida no início dos anos 2000. Posteriormente, o efeito da demanda das exportações foi complementado pela expansão do consumo interno baseado em crédito e mais recentemente por aumentos de gastos públicos. Argumentamos que o crescimento atual, baseado em aumento da demanda, é passageiro, posto que é insustentável. Crescimento puxado pela demanda tende a redundar em inflação quando a capacidade de utilização da economia chega ao seu limite. No caso do setor externo, a inversão rápida para os saldos negativos em transações correntes, ao invés de estimular o crescimento atuarão no sentido de travá-lo. A continuidade do crescimento da economia brasileira dependerá do comportamento do investimento. Para o país continuar crescendo de forma sustentada é preciso que o investimento ocupe o lugar do consumo como determinante da expansão. Mas isto é improvável, se o regime macroeconômico continuar como está, com juros altos, câmbio valorizado e carga tributária elevada. A tendência, se nada for feito, é de transformação do início de um processo de crescimento longo e sustentado no sétimo episódio de crescimento passageiro.
\end{abstract}

Palavras Chave: Crescimento. Setor Externo. Macroeconomia.

\section{INTRODUÇÃO}

O atual ciclo de expansão da economia brasileira iniciado em 2004 apresenta boas perspectivas em função da mudança de uma trajetória de aproximadamente 25 anos de estagnação, ao mesmo tempo em que se depara com um grande desafio: como manter a sustentabilidade desse crescimento ao longo do tempo?

O cenário atual torna esse desafio ainda mais complexo diante de pressão inflacionária liderada pela alta dos preços das commodities no mercado internacional, que

\footnotetext{
* Doutorando em Desenvolvimento Econômico pela UFPR, e professor do Departamento de Economia da mesma instituição. Endereço eletrônico: joaobasilio@unibrasil.com.br.

** Mestre em Desenvolvimento Econômico pela UFPR, e professor do Departamento de Economia da mesma instituição. Atualmente é vice-coordenador do curso de Ciências Econômicas da UFPR. Endereço eletrônico: marciocruz@ufpr.br.
} 
tenderá a gerar uma reação por parte do Banco Central. O problema é que ao tentar conter a propagação da inflação com o aumento da taxa de juros, principal instrumento do BC na condução de política monetária, sendo esse um comportamento esperado por conta do regime de metas, as taxas reais de juros no Brasil ficarão ainda mais atrativas para o capital estrangeiro. Cabe lembrar que a concessão do Investment Grade ao Brasil por duas agências de risco nos últimos meses tende a refletir em um sinal de menor risco com relação ao país, ao mesmo tempo em que o Banco Central dos Estados Unidos (Fed) sinaliza com uma tendência de queda da taxa de juros daquele país, tido como referência dos juros internacionais. Desta forma, a entrada de capitais tenderá a valorizar ainda mais a taxa real de câmbio, que tem apresentado um processo contínuo de valorização desde meados de 2003.

A valorização do câmbio, acompanhada da expansão da economia, tenderá a resultar na piora dos resultados em transações correntes, o que tem sido percebido já em 2008. Neste caso, a história recente do país, demonstra que em geral o setor externo se apresenta como uma importante restrição ao crescimento econômico.

Apesar de não se comprometer com qualquer meta de taxa de câmbio, num regime de câmbio flexível, o elevado spread proporcionado pela taxa de juros do Brasil tende a resultar na valorização cambial, que é benéfica ao controle da inflação, principalmente pelo fato desta estar sendo impulsionada por preços determinados no mercado internacional.

As questões sobre as quais este artigo se propõe a refletir são: o Brasil está diante de um dilema entre o equilíbrio interno e externo? Para manter um nível de crescimento, sem que haja pressão inflacionária, será necessário conviver com déficit em transações correntes? Quais as prováveis conseqüências desta opção? Se de fato existe esse conflito dos objetivos a serem atingidos, quais as alternativas são factíveis com o cenário atual?

\section{CRESCIMENTO DE CICLO CURTO E CRESCIMENTO SUSTENTADO}

O crescimento sustentado envolve um processo dinâmico de expansão do nível de produto e geração de empregos que permita ao país crescer a uma taxa acima da taxa de crescimento populacional ao longo do tempo, de forma que sejam formadas as condições de redução da injustiça social consubstanciada na péssima distribuição de renda e riqueza, herdada de um modelo de desenvolvimento mal orientado no passado.

O crescimento será sustentado caso os impulsos de expansão da atividade econômica durem uma década inteira ou mais e sem que as formas de financiamento no curto e médio prazo se constituam em restrições no longo. O que estamos aqui chamando de 
crescimento sustentado comporta, portanto, dois requisitos: um diz respeito à geração de equidade, na forma de distribuição de renda e riqueza, o outro diz respeito à capacidade endógena de financiamento, de forma que haja equilíbrio intertemporal entre endividar-se no presente sem inviabilizar as gerações futuras.

O padrão de crescimento da economia brasileira nunca atendeu aos dois requisitos simultaneamente. O mais intenso período de crescimento, que coincidiu com a ditadura militar, proporcionou crescimento sem equidade e sem equilíbrio intertemporal. É possível alegar que o problema do equilíbrio intertemporal não existiria se não tivessem ocorrido: a crise de petróleo em 1973 e 1979; o fenômeno da estagflação; e a desregulação do sistema financeiro mundial além das flutuação das moedas promovidas pelo fim da era Bretton Woods em 1971, ou então, as crises financeiras da década de 1990. Entretanto, as crises cíclicas do sistema capitalista tendem a ser uma regra e não uma exceção. Logo, um processo de crescimento que respeite essas condições deve considerar ex ante esse comportamento sistêmico.

Em relação à equidade, tomando uma taxa de crescimento populacional de $2 \%$ a.a., o Brasil precisaria crescer 4\% a.a. ininterruptamente durante 35 anos para ter sua atual renda per capita de R\$13.517,00 (IBGE, Contas Nacionais 2007) dobrada de tamanho, como précondição para distribuir os frutos do crescimento e gerar com isso mais equidade, enquanto cresce. No entanto, o crescimento econômico de longo prazo não é uma subida suave e contínua. Ciclos econômicos se sucedem ao longo ou em torno de uma trajetória média de crescimento, geralmente assumida como sendo a linha de tendência de cada país.

A Tabela 1 mostra o que está acontecendo com a taxa de crescimento de longo prazo ou com a linha de tendência da economia brasileira. Nos últimos 40 anos o país cresceu a uma taxa média de 5,24\% a.a. O número em si pode parecer alentador, pois a taxa de crescimento foi acima do dobro do crescimento populacional. Entretanto, esse período inclui o ciclo de industrialização de 1968-1980, um período que contrasta a ausência de liberdades individuais e democracia com o acelerado crescimento proveniente da presença de um plano nacional de industrialização. Como é vastamente reconhecido na literatura e história econômica e social, o robusto crescimento do período 1968-1980 não proporcionou uma melhoria na distribuição da renda e da riqueza. Ao contrário, concentrou-a em níveis expressivos, se comparado à experiência de outras economias que fizeram sua transição para industrialização com mais equidade. 
TABELA 1 - CRESCIMENTO REAL MÉDIO ANUAL DO BRASIL

\begin{tabular}{lc}
\multicolumn{1}{c|}{ PERÍODO } & \% A.A. \\
\hline Período da ditadura (1964-1980) & $7,57 \%$ \\
Últimos 40 anos (1968-2007) & $5,54 \%$ \\
Últimos 30 anos (1978-2007) & $3,47 \%$ \\
Últimos 20 anos (1988-2007) & $2,82 \%$ \\
Últimos 10 Anos (1998-2007) & $2,75 \%$ \\
Últimos 5 anos (2003-2007) & $3,59 \%$ \\
\hline
\end{tabular}

FONTE: IBGE (2008). Elaboração própria.

O crescimento acelerado entre 1968 e 1980 não foi sustentável no sentido social, pois culminou na atual estrutura concentrada de renda e riqueza. Também não o foi no sentido financeiro, pois a década de 80 passou para a história econômica do Brasil como a década perdida. Um dos fatores que contribuiu para o baixo crescimento da década inteira foi a crise da dívida externa, herdada do período de crescimento acelerado do período da ditadura.

A ausência de sustentabilidade fica evidenciada nas décadas seguintes em função do rebaixamento da linha de tendência de longo prazo. Se tomarmos a taxa média de crescimento, calculada em diferentes horizontes de tempo, percebe-se que ela vem caindo e somente nos últimos cinco anos tem se recuperado, todavia encontra-se abaixo da média dos últimos 40 anos.

A dificuldade de manter um ritmo de crescimento sustentado ao longo do tempo é mostrada no Gráfico 1, a seguir. As áreas em destaques significam episódios de recessão ou desaceleração aguda do ritmo de crescimento.

\section{GRÁFICO 1 - CICLOS ECONÔMICOS NO BRASIL (TAXAS ANUAIS DE CRESCIMENTO)}

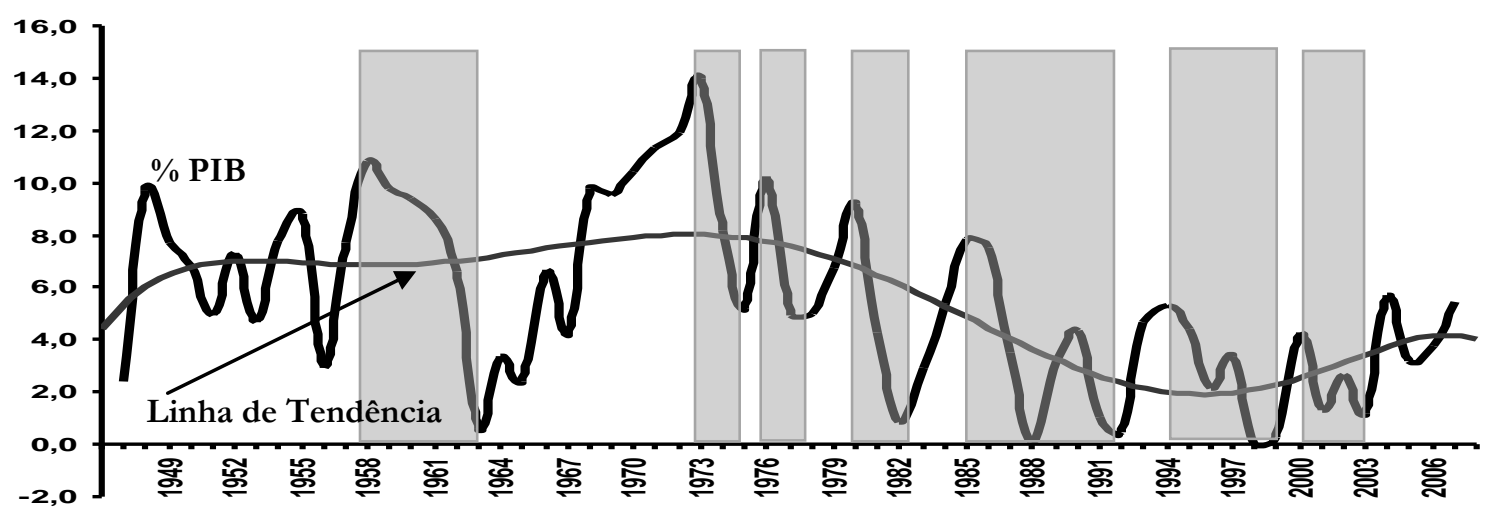

FONTE: IBGE apud IPEADATA (2008). 
Num retrospecto de 60 anos, houve apenas dois ciclos longos de crescimento. Um durou 15 anos, de 1948 a 1962. O segundo durou 16 anos, de 1966 a 1981. Desde então o processo de crescimento foi extremamente errático, caracterizado por ciclos curtos, que alternam crescimento e crise não caracterizando um processo sustentado de crescimento. Como pode ser visto no gráfico, após 1973, ocorreram 6 ciclos curtos de crescimento e recessão, que no conjunto geraram o rebaixamento da linha de tendência de longo prazo da economia.

Os ciclos brasileiros sempre estiveram associados ao desempenho das contas externas, mais especificamente à balança comercial e ao balanço de movimento de capitais. $\mathrm{Na}$ fase de industrialização, os dois ciclos longos de crescimento foram acompanhados de déficits em transações correntes, compostos em grande parte pelo saldo negativo da balança comercial sob o pretexto importar para implantar a indústria moderna no país. A substituição de importações, que existiu até fins dos anos 1970, implicava em constantes déficits em transações. No período seguinte, nos anos 1980, a taxa média de crescimento caiu em função da insustentabilidade de manter o crescimento sendo continuamente financiado com poupança externa, isto é, com déficits em transações financiados com base no capital financeiro.

O Gráfico 2 a seguir mostra a relação entre crescimento e saldo das transações correntes. Observa-se que os ciclos de crescimento entre 1948-62 e 1964-80 são acompanhados por déficits cumulativos em transações correntes, sendo um indício do papel relevante que teve o financiamento externo em ambos os processos. As transações correntes também apresentam déficit cumulativo entre 1995-2001. Há uma literatura bastante ampla em torno desta relação, analisando o caso brasileiro, com destaque para os modelos de crescimento com restrição externa desenvolvidos por Thirlwall e McCombie. Esta literatura afirma que a taxa de crescimento equilibrado de longo prazo de um país depende de como as exportações e as importações variam quando o PIB cresce. $\mathrm{O}$ aumento das exportações causa um aumento do PIB. No entanto o próprio crescimento do PIB faz crescer as importações de forma que o saldo da balança comercial tende a se equilibrar no longo prazo. Prevê a existência de uma taxa de crescimento de equilíbrio do PIB na qual o aumento das exportações é igual ao aumento das importações. Esta taxa seria a tendência de longo prazo em torno da qual ocorreriam ciclos de expansão e contração do PIB. 
GRÁFICO 2 - CRESCIMENTO DO PIB E TRANSAÇÕES CORRENTES (TAXAS ANUAIS DE CRESCIMENTO)

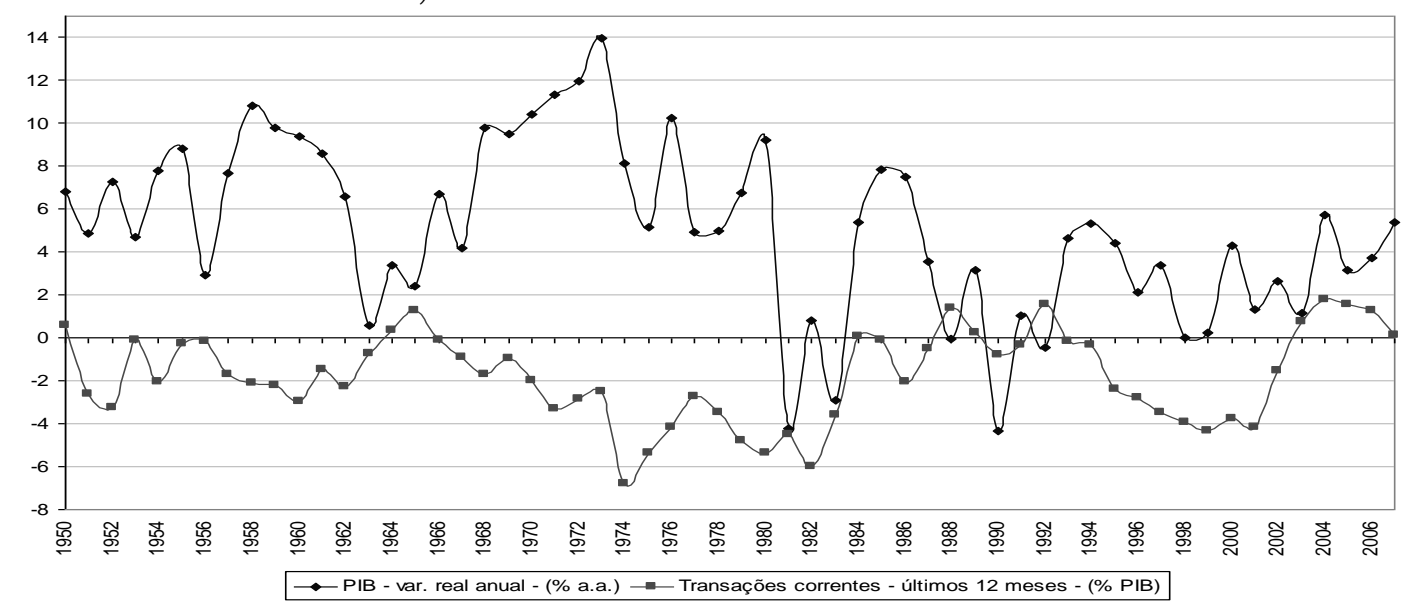

FONTE: IBGE apud IPEADATA (2008).

Chama à atenção o fato de que o atual ciclo de crescimento da economia brasileira, iniciado em 2004, estava até então, apresentando uma característica distinta dos ciclos anteriores, pelo fato de estar acompanhado de resultados positivos em transações correntes. Porém, percebe-se que a partir de 2007 há uma mudança nesta tendência, a qual apresenta perspectiva de uma intensificação do déficit a partir de 2008. Isto leva a crer que, a despeito do otimismo exagerado das autoridades públicas, o que teremos é, talvez, mais período de crescimento curto. O déficit externo (aumento das importações) terá efeitos negativos sobre o PIB com redução da taxa de crescimento. A depender da dinâmica do setor externo, e em ficando tudo como está hoje, é provável que tenhamos crescimento menor do PIB nos próximos anos. $\mathrm{Na}$ próxima seção explicamos porque o padrão de crescimento atual ameaça em se transformar no sétimo episódio de ciclo curto.

\section{CRESCIMENTO, CONSUMO E INVESTIMENTO}

O atual ciclo de crescimento, 2004-2007, tem se caracterizado pelo aumento da demanda com base nos setores interno e externo (via exportações). O consumo interno aumentou devido ao crescimento da massa de rendimentos das classes $\mathrm{C}$ e $\mathrm{D}$, ao aumento do crédito ao consumo e de uma política fiscal de gastos em custeio expansionista; o consumo externo cresceu em função do aumento das exportações a partir de 2002, estimuladas pelo câmbio desvalorizado da época e pela conjuntura internacional favorável aos exportadores de commodities, esta trajetória foi significantemente influenciada pelo crescimento dos países asiáticos.

A sustentabilidade do processo de crescimento, inicialmente estimulado pela ampliação do consumo depende da ampliação da capacidade produtiva. Uma das condições 
necessárias para obtenção de crescimento sustentável de longo prazo é a realização de investimentos em montante suficiente para que este investimento crie demanda adicional para a própria ampliação do capital que o mesmo expandiu. Isto é, a taxa de investimento deve ser tal que efeito demanda e o efeito capacidade do investimento sejam iguais. Se o efeito capacidade for maior que o efeito demanda, no período seguinte haverá excesso de capacidade, e com isso redução do investimento. Por outro lado, o excesso do efeito demanda, pode gerar pressões inflacionárias.

Mas o que se observa em relação ao investimento é que a sua proporção em relação ao PIB permanece baixa, embora esteja aumentando. Ela foi de 16,5\% em 2006, aumentou para $17,6 \%$ em 2008 e para 18,9\% no primeiro trimestre de 2008 . O aumento da proporção do investimento em relação ao PIB é um indicador de sustentabilidade do crescimento. No entanto, a proporção é ainda muito baixa para garantir a expansão da capacidade de oferta nos níveis necessários.

A constatação de que o crescimento foi, de fato, puxado pelo consumo pode ser observada pela trajetória de três importantes variáveis. O consumo das famílias, os gastos do governo e o saldo da balança comercial (exportações menos importações).

Pela Tabela 2A pode-se observar as altas taxas de crescimento das exportações no período 2001-2004. Na sequência, em 2004-2005 a variável que expandiu a demanda foi o consumo do governo, que cresceu 4,69\% e 6,89\% ao ano respectivamente. O crescimento de 3,76\%aa de 2006 pode ser explicado pela repercussão dos gastos do governo de 2005 e pela tímida recuperação do investimento. Em 2007, os principais componentes do crescimento foram o consumo privado (6,26\%aa) e investimento (12,15\%aa). Tendo em vista que o consumo representa quase $2 / 3$ do produto total e o investimento apenas $17 \%$ em 2007, podese concluir facilmente que o alto crescimento de 2007 só foi possível pela dinâmica imposta pelo consumo das famílias.

\begin{tabular}{l|r|r|r|r|r|r|r}
\hline TABELA 2A- CONTAS NACIONAIS VARIAÇÃO PERCENTUL POR PERÍODO \\
\hline Período & PIB & $\begin{array}{c}\text { Consumo } \\
\text { das } \\
\text { famílias }\end{array}$ & Consumo governo & fo gBKF & $\begin{array}{c}\text { Variação } \\
\text { dos } \\
\text { estoques }\end{array}$ & Exportações & Importações \\
\hline 2001 & 1,31 & 0 & 4,44 & 2,66 & $-27,24$ & 23,67 & 16,78 \\
2002 & 2,66 & $-0,22$ & 6,76 & $-1,38$ & $-114,43$ & 18,22 & $-4,64$ \\
2003 & 1,15 & 1,58 & $-4,72$ & $-5,65$ & $-432,93$ & 8,16 & $-2,47$ \\
2004 & 5,71 & 1,95 & 4,69 & 11,35 & 142,26 & 15,88 & 9,8 \\
2005 & 3,16 & 4,01 & 6,89 & 2,14 & $-70,51$ & $-4,99$ & $-5,3$ \\
2006 & 3,76 & 3,9 & 3,52 & 7,42 & 33,8 & $-0,06$ & 4,97 \\
2007 & 5,42 & 6,26 & 4,63 & 12,15 & 3 & 0,3 & 11,51 \\
\hline
\end{tabular}

FONTE: IBGE (2008). Reproduzido em www.boletimdeconjuntura.ufpr.pr. 
TABELA 2 B - CONTAS NACIONAIS - PROPORÇ̃̃O DO PIB

\begin{tabular}{l|c|c|c|c|c|c|c}
\hline Período & PIB & $\begin{array}{c}\text { Consumo } \\
\text { das } \\
\text { famílias }\end{array}$ & do governo & Consumo & $\begin{array}{c}\text { Variação } \\
\text { dos } \\
\text { estoques }\end{array}$ & Exportações & Importações \\
\hline 2001 & $100,00 \%$ & $64,40 \%$ & $19,10 \%$ & $16,80 \%$ & $1,40 \%$ & $10,00 \%$ & $11,70 \%$ \\
2002 & $100,00 \%$ & $63,50 \%$ & $19,70 \%$ & $17,10 \%$ & $1,00 \%$ & $12,20 \%$ & $13,50 \%$ \\
2003 & $100,00 \%$ & $61,70 \%$ & $20,50 \%$ & $16,40 \%$ & $-0,10 \%$ & $14,00 \%$ & $12,50 \%$ \\
2004 & $100,00 \%$ & $62,00 \%$ & $19,30 \%$ & $15,30 \%$ & $0,50 \%$ & $15,00 \%$ & $12,10 \%$ \\
2005 & $100,00 \%$ & $59,80 \%$ & $19,10 \%$ & $16,10 \%$ & $1,10 \%$ & $16,40 \%$ & $12,60 \%$ \\
2006 & $100,00 \%$ & $60,30 \%$ & $19,80 \%$ & $15,90 \%$ & $0,30 \%$ & $15,10 \%$ & $11,50 \%$ \\
2007 & $100,00 \%$ & $60,40 \%$ & $19,80 \%$ & $16,50 \%$ & $0,40 \%$ & $14,60 \%$ & $11,70 \%$ \\
\hline
\end{tabular}

FONTE: IBGE (2008).

O padrão do atual ciclo de crescimento é claramente impulsionado pelo lado da demanda, com pouca variação na capacidade de oferta. Se analisarmos a ordem dos acontecimentos, desde 2003, veremos que o ciclo atual obedeceu a seguinte lógica sequencial:

$$
\begin{aligned}
\text { exportações } & \rightarrow \text { gasto público } \rightarrow \text { consumo privado } \\
2001-2004 & \rightarrow \text { 2004-2005 } \rightarrow \text { 2005-2007 }
\end{aligned}
$$

O problema da manutenção das taxas atuais de crescimento e mesmo sua ampliação depende do que irá acontecer com o investimento (FBKF) nos próximos anos. A proporção de investimento em relação ao PIB iniciou uma recuperação a partir de 2007, atingindo 18,3\% no primeiro trimestre de 2008. O crescimento do PIB de 2007 e em especial do primeiro trimestre de 2008 é resultado de uma sobreposição dos efeitos do aumento da demanda baseada em consumo, gasto público e exportação no passado, com os primeiros sinais de recuperação do investimento.

O desafio atual do país é encontrar as condições macroeconômicas de curto e médio prazo que permitam que nos próximos anos a variável investimento ocupe definitivamente, e por um longo período, o lugar do consumo agregado enquanto determinante do crescimento. Esta mudança é pré-requisito para determinação de um modelo de crescimento sustentado. A seção seguinte tratará deste tema. $\mathrm{Na}$ atual combinação de políticas macroeconômicas, não há nada que possa indicar a existência de motivos para que haja esta conversão ocorra por muito tempo.

O esgotamento do efeito do consumo no ciclo atual de crescimento é possível por dois motivos básicos. O primeiro pelo comportamento dos consumidores. Eles não podem se endividar recursivamente. Em algum momento terão que utilizar sua renda corrente para amortização de dívidas e juros, reduzindo temporariamente seu consumo. Tendo em vista o elevadíssimo custo do crédito ao consumo no país, a transferência de renda do orçamento do consumidor endividado não permite que seu consumo continue crescendo. $\mathrm{O}$ custo do 
financiamento atua no sentido de diminuir a renda disponível para o consumo, de forma que é possível prever uma redução no seu ritmo de expansão. A única possibilidade de expansão futura do consumo em ritmo acelerado é a incorporação de novos trabalhadores no processo produtivo e o aumento do salário real. Como o salário real cresce à custa da participação dos lucros na renda, em algum momento este canal também se esgota, não constituindo numa fonte permanente de estímulo ao crescimento. O segundo motivo básico é inversão nas contas externas, que até 2007 eram positivas. A diminuição do saldo da balança comercial devido ao aumento das importações, somados ao aumento dos déficits em serviços e rendas, transformou o saldo em transações corrente deficitário. De ora em diante, dos dois determinantes básicos da demanda um, o consumo, tende a seguir o crescimento ao invés de impulsioná-lo, e o outro, o setor externo, tende a freá-lo, tanto pela valorização do câmbio quanto pela desaceleração da economia mundial.

Além do auto-esgotamento da capacidade de financiamento do consumo, a expansão da demanda já aproximou a economia do limite de sua capacidade de produção, e daqui para frente, ampliação da demanda sem ampliação da oferta implica em inflação. Neste caso, sem a ampliação da oferta, o que resta ao país é o costumeiro stop-and-go que já observamos nos últimos seis ciclos de crescimento, destacados no Gráfico 1, acima.

A única opção de crescimento sustentado passa pela ampliação dos investimentos. Não negamos a importância da participação do Estado no processo, mas grande parte do crescimento sustentado de longo prazo caberá aos investimentos privados. Neste cenário a participação do mercado financeiro e de capitais como meios de captação de recursos para financiar os investimentos tende a ser relevante. Aliás, boa parte do crescimento da relação investimento/PIB de 2007 deve-se a financiamento obtido no mercado de capitais, que bateu recorde de emissões primárias, atingindo $\mathrm{R} \$ 33,1$ bilhões em 2007 contra apenas $\mathrm{R} \$ 0,477$ bilhões em 2006.

Dada a centralidade da variável investimento na obtenção de crescimento sustentado, doravante as preocupações e decisões naturalmente se dirigem para as condições macroeconômicas de médio prazo que devem ser atendidas para que o investimento ocorra.

\section{CONJUNTURA MACROECONÔMICA E CRESCIMENTO}

Embora as expectativas atuais de boa parte dos agentes, privados e públicos sejam otimistas quanto ao crescimento futuro, não temos garantias que elas se mantenham. Expectativas, por constituição, são voláteis. As expectativas atuais sobre crescimento refletem 
em parte um contágio pelo sucesso do passado recente. No ciclo atual, o investimento privado começou a crescer apenas em 2007 como uma resposta adaptativa a três anos consecutivos de aumento da demanda interna. As dúvidas quanto à sazonalidade ou transitoriedade do crescimento foram exauridas no início de 2007 quando as expectativas futuras mudaram e as projeções de crescimento subiram justificando o aumento observado no investimento em 2007 e início de 2008.

No entanto a mudança no setor externo, a ameaça de inflação e políticas fiscais contraditórias emitem sinais negativos para o médio prazo. As expectativas podem mudar, como de fato estão fazendo, com o próprio governo acenando para um ritmo de crescimento menor no futuro imediato. O cenário macroeconômico exige ajustes para que o crescimento migre definitivamente para uma tendência sustentada, apoiada em expansão do investimento.

Atualmente há três grandes desafios macroeconômicos a serem superados, de difícil equalização simultânea: desajuste no setor externo, ameaça de inflação e reduzida capacidade fiscal do setor público. No centro de todos está a política monetária, que ao determinar a taxa básica de juros, afeta as condições de equilíbrio do setor externo e a capacidade de financiamento do Estado.

$\mathrm{Na}$ seção seguinte apresentamos algumas reflexões sobre as questões apresentadas no início do artigo.

\subsection{O BRASIL ESTÁ DIANTE DE UM DILEMA ENTRE EQUILÍBRIO INTERNO E EXTERNO?}

A resposta a essa questão depende a princípio da definição utilizada entre equilíbrio interno e externo. Se considerarmos equilíbrio interno como sendo um nível de atividade econômica que proporciona um crescimento da renda per capita ao longo do tempo sem que haja pressões inflacionárias (no caso do regime de metas de inflação, havendo o cumprimento da meta estabelecida); e se considerarmos equilíbrio externo como sendo uma situação na qual o país apresenta equilíbrio no balanço de pagamentos, então as evidências nesta direção não são muito positivas e fortes para o curto prazo.

O Gráfico 3 demonstra que o balanço de pagamentos tem se apresentado positivo, com um ingresso expressivo na conta capital e financeira, o qual resultou no aumento das reservas internacionais do país, sem que houvesse necessidade de financiamento, em função de déficits das transações correntes, no período 2004-07. 
GRÁFICO 3 - BALANÇO DE PAGAMENTO DE PAGAMENTOS, TRANSAÇOES CORRENTES E CONTA CAPITAL (SALDO US\$ MILHÕES)

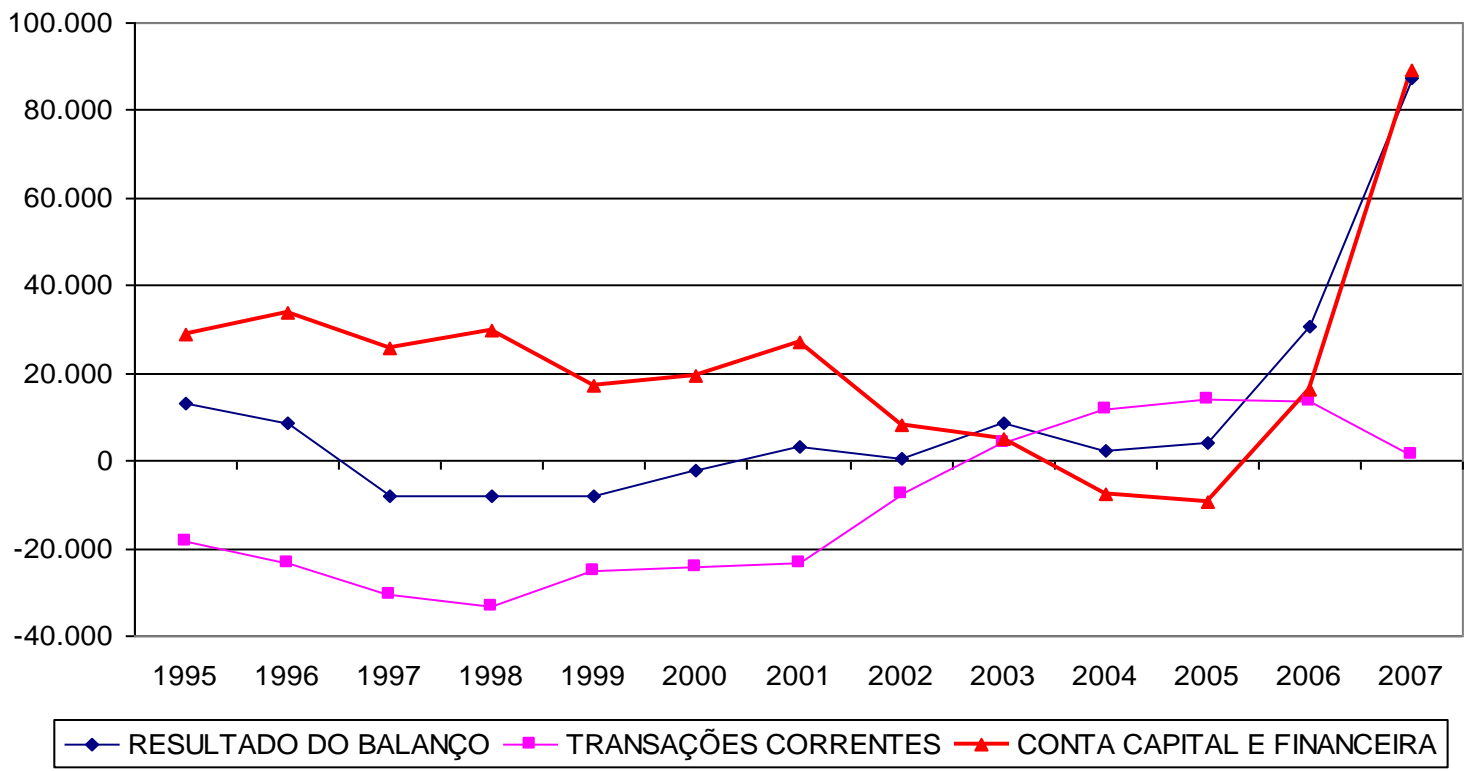

FONTE: BACEN (2008).

Porém, o problema é que o resultado em transações correntes está se invertendo, sinalizando no período recente uma forte tendência ao déficit no início de 2008. Continuando esta tendência deficitária, o problema passa a estar relacionado com a capacidade de a economia brasileira manter o financiamento externo.

Consideremos o equilíbrio externo como uma situação na qual o país não apresenta necessidade de financiamento externo, ou seja, mantém o equilíbrio ou superávit em transações correntes. Neste caso, a decisão de um aumento na taxa de juros (caso se reverta em aumento da taxa real de juros ${ }^{1}$ ), na tentativa de garantir as condições de equilíbrio interno, preservando poder de compra da moeda, tenderá a se reverter numa piora das transações correntes, provavelmente acompanhada num primeiro momento por um aumento da entrada de capital seguida de maior valorização cambial.

Portanto, dois problemas surgem deste processo: a) o risco de perda de competitividade da economia brasileira em alguns setores, os quais terão dificuldade de se recuperar posteriormente; b) o risco de uma crise financeira que resulte na indisposição de financiar o crescimento da economia brasileira, resultando em um fluxo de saída de capitais que pode vir a gerar a desvalorização cambial, pressionando a inflação.

O modelo de economia aberta com mobilidade plena de capitais e câmbio flutuante, combinado com sistema de metas de inflação atualmente em curso, é eficiente do ponto de

\footnotetext{
${ }^{1}$ Diante da pressão inflacionária isso irá depender do gradualismo do Banco Central.
} 
vista do combate à inflação de demanda, mas não tão eficiente do ponto de vista de sustentar o crescimento.

Neste modelo o Banco Central combate inflação simplesmente elevando a taxa básica de juros na tentativa de conter as expectativas de inflação. Caso as expectativas não se reduzam então a punição em termos de política monetária restritiva deverá ser exercida sob pena de perda de credibilidade. Se as expectativas de inflação reduzem, a inflação efetiva diminui sem sacrifícios sociais em termos de redução do nível de renda ou aumento de desemprego. Neste contexto, para que possa fazer uso irrestrito da política monetária, é preciso abrir mão de qualquer tipo de estabilidade cambial. $O$ câmbio precisa ser deixado livre, como variável de ajuste. Controlando a taxa de juros (e moeda), com a finalidade de controlar preços e salários, o Banco Central precisa deixar o câmbio flutuar como meio forma de manter o balanço de pagamentos em equilíbrio. $\mathrm{O}$ efeito de um aumento da taxa de juros tem um duplo impacto positivo sobre preços, e um duplo impacto negativo sobre o crescimento.

O duplo impacto dos juros sobre a inflação (preços) decorre do efeito negativo exercido sobre o consumo e o investimento ao inibir crédito em geral, e do efeito sobre a valorização cambial. O capital financeiro especulativo aflui para mercados com altas taxas de juros interna aumentando a oferta de moeda estrangeira e causando valorização do câmbio. As importações tornam-se mais baratas e competitivas dificultando remarcações de preços. As exportações, por sua vez, se tornam menos rentáveis de forma que se amplia a oferta interna reforçando os obstáculos à remarcação de preços.

O duplo impacto negativo dos juros sobre o crescimento decorre do próprio efeito demanda do consumo, investimento, exportações (em queda) e importações (em alta), e também do efeito sobre a formação de expectativas quanto ao equilíbrio do mercado financeiro. Ao permitir o câmbio se valorizar, o país se vê forçado a equilibrar os déficits em transações reais com superávits na conta capital atraindo mais capital estrangeiro. Para isso é preciso juros atrativos. Este regime macroeconômico impõe uma trava para redução dos juros e empurra os agentes financeiros para posturas especulativas.

Este é o grande entrave que regime monetário-cambial atual deverá impor ao crescimento sustentado, se nada mudar. O cenário de conjuntura macroeconômica no médio prazo está conduzindo o país para uma repetição da história dos últimos dois ciclos recessivos, por conta do déficit em transações correntes, ao combinar câmbio valorizado e juros altos. 
4.2 PARA MANTER UM NÍVEL DE CRESCIMENTO, SEM QUE HAJA PRESSÃO INLACIONÁRIA, SERÁ NECESSÁRIO CONVIVER COM DÉFICIT EM TRANSAÇÕES CORRENTES?

No curto prazo isso dependerá basicamente do comportamento do investimento. Ou seja, se a capacidade produtiva da economia brasileira conseguir acompanhar o aquecimento da demanda, o Banco Central poderá recorrer a uma política monetária menos agressiva, na tentativa de conter a propagação da inflação.

Neste caso, um indicador positivo refere-se ao fato de que a formação bruta de capita tem aumentado sua participação no crescimento do PIB. Desta forma, a tendência à ampliação dos investimentos poderá conter parcialmente a pressão sobre o nível de preços da economia e conseqüentemente a necessidade de um ciclo de aumento expressivo da taxa de juros.

GRÁFICO 3 - CONTRIBUIÇÃO DO INVESTIMENTO NO CRESCIMENTO DO PIB - VAR.(\%)

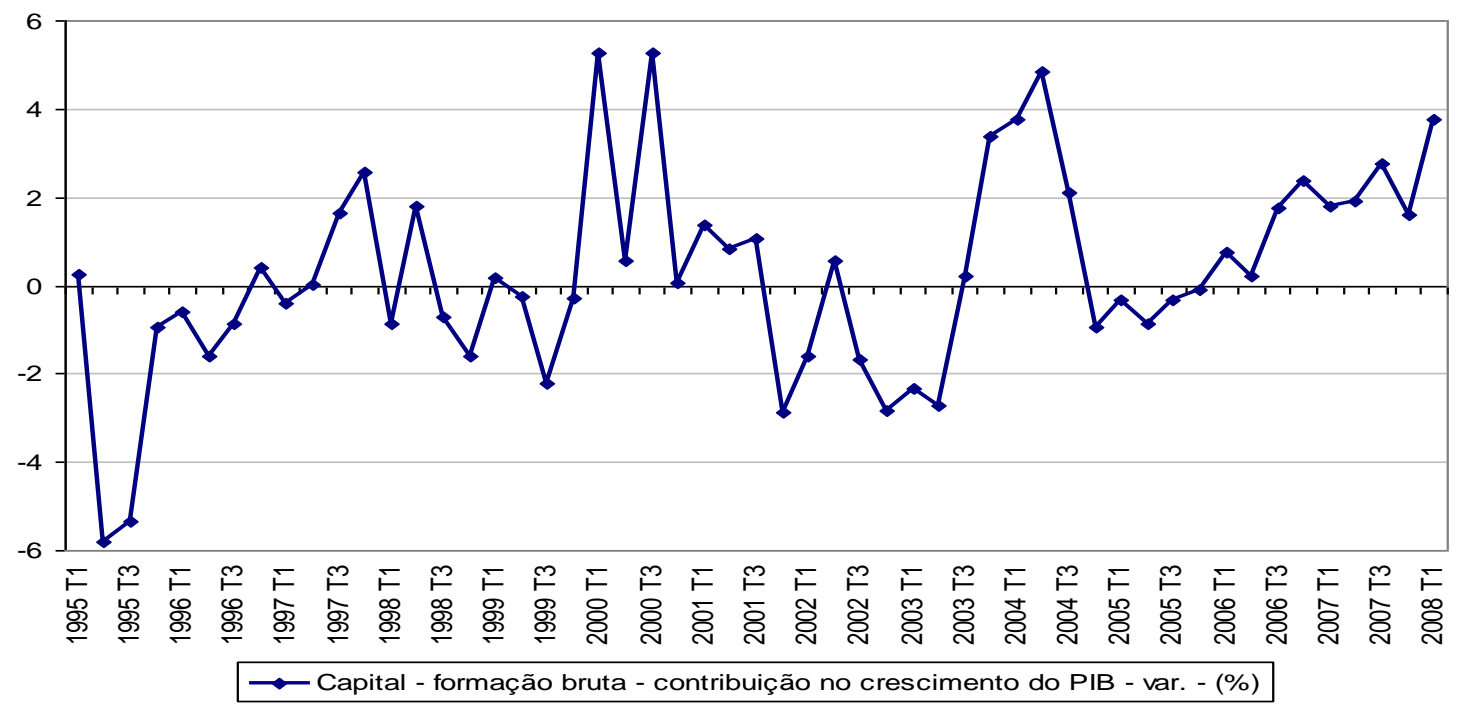

FONTE: SCN - IBGE apud IPEADATA (2008).

\subsection{SE DE FATO EXISTE ESSE CONFLITO DE OBJETIVOS A SEREM ATINGIDOS, QUAIS AS ALTERNATIVAS FACTIIVEIS COM O CENÁRIO ATUAL?}

A combinação de taxas de juros e gastos elevados impõe a necessidade contínua de manutenção elevada da carga tributária sob pena de elevação da relação dívida/PIB. A lógica do regime monetário-fiscal em curso é de certa forma perversa no longo prazo. Não há espaço suficiente no orçamento para que o investimento público se amplie, de forma a complementar os investimentos privados e garantir a sustentabilidade do crescimento. Nas condições atuais a expansão do investimento público só seria possível mediante dois caminhos, ambos improváveis: emissão de títulos ou aumento de arrecadação. O primeiro, 
não é intertemporalmente sustentável, dado que a relação dívida/PIB já é elevada. O segundo também, pois a carga tributária já ultrapassou o limite do tolerável, e mesmo que pudesse ser implementada, poderia ser questionada, sob o argumento de que o aumento de arrecadação apenas transfere a capacidade de investimento do setor privado para o público (o chamado efeito crowding-out).

\section{CONSIDERAÇÕES FINAIS}

A inflexão na trajetória de crescimento deste último ciclo de expansão levanta questões importantes para o futuro do país. A importância e a necessidade de continuar crescendo requer que o país discuta o seu padrão atual de crescimento, bem como seu regime macroeconômico, pois este carrega algumas contradições e inconsistência interna, quando o objetivo for o crescimento. A sustentabilidade do crescimento, como pré-condição para que haja uma diminuição de desigualdades, requer um regime macroeconômico: a) cujo dinamismo não seja bloqueado ou restringido pelo desequilíbrio do setor externo real; b) que substitua crescimento baseado em consumo por crescimento baseado em investimento a fim que pressionar a inflação; c) com uma política fiscal de gastos e tributação coordenada e não contraditória como é atualmente; d) que evite especulações financeiras por conta de uma taxa de juros excessivamente alta em relação à taxa internacional e por fim; e) com um regime cambial menos propício a grandes flutuações que reforçam o estímulo especulativo dos agentes.

\section{REFERÊNCIAS}

IBGE. Série histórica do Sistema de Contas Nacionais. Disponível em <www.ibge.gov.br>. Acesso em: 10/06/08.

Banco Central do Brasil (BACEN). Série histórica do Balanço de Pagamentos. Disponível em: $<$ www.bcb.gov.br>. Acesso em: 10/06/08.

IPEADATA. Série histórica do Sistema de Contas Nacionais. Disponível em: <www.ipeadata.gov.br>. Acesso em: 10/06/08. 